\title{
First Record of the Stichaeid Fish Chirolophis saitone (Perciformes: Stichaeidae) from Korea
}

\author{
Maeng Jin Kim, Jung Hwa Choi, Dong Woo Lee, Jung Yun Kim and Kwang Ho Choi* \\ Fisheries Resources Management Division, National Fisheries Research and Development Institute, Busan 619-705, Korea
}

\begin{abstract}
One specimen of Chirolophis saitone, belonging to the family Stichaeidae, was collected by a bottom trawl in the southern area of the Yellow Sea. The present specimen was characterized by 52 dorsal fin spines, 38 anal fin spines, a caudal fin with four vertical dark bands and an orbital region with three pairs of branched cirri. We propose a new Korean name, "Jak-eun-goe-do-ra-chi", for C. saitone.
\end{abstract}

Key words: First record, Chirolophis saitone, Stichaeidae, Yellow Sea

\section{Introduction}

The genus Chirolophis of the family Stichaeidae, is widely distributed in cold waters of the Pacific and Atlantic Oceans, and is characterized by dorsal fins with 50-62 spines, anal fins with one spine and 35-47 soft rays, and branched cirri on the top of the head, the cheek, and the chin. To date, seven species of Chirolophis have been reported worldwide, with three specie, C. japonicus, C. snyderi, and C. wui from Japan (Hatooka, 2002), three species, $C$. japonicus, $C$. saitone, and $C$. wui from China (Liu et al., 2005) and three species, C. japonicus, C. snyderi, and C. wui from Korea (Kim et al., 2005).

During a survey for fisheries resources in Korean waters, one specimen of $C$. saitone was collected by a bottom trawl in the southern coastal waters of the Yellow Sea on March 30, 2011. The morphological characters of $C$. saitone are described herein, and the species added to the list of Korean fish fauna.

\section{Materials and Methods}

Counts and measurements of the specimen follow the meth- ods of Hubbs and Lagler (2004). The examined specimen was deposited at the National Fisheries Research and Development Institute (NFRDI), Korea.

\section{Results and Discussion}

\section{Chirolophis saitone (Jordan and Snyder, 1902)}

(new Korean name: Jak-eun-goe-do-ra-chi) (Table 1, Fig. 1)

Bryostemma saitone Jordan and Snyder, 1902: 467 (type locality: Aomori, Japan)

Chirolophis saitone: Makushok, 1958: 61; Ueno, 1966: 439; Lindberg and Krasyukova, 1975: 77; Liu et al., 2005: 202.

\section{Material examined}

Chirolophis saitone $(n=1): 75.9 \mathrm{~mm}$ standard length (SL), bottom trawl, Yellow Sea, Korea, Mar 30, 2011.
Open Access http://dx.doi.org/10.5657/FAS.2013.0195

This is an Open Access article distributed under the terms of the Creative Commons Attribution Non-Commercial License (http://creativecommons, org/licenses/by-nc/3.0/) which permits unrestricted non-commercial use, distribution, and reproduction in any medium, provided the original work is properly cited. pISSN: 2234-1749 eISSN: 2234-1757
Received 8 March 2013; Revised 9 April 2013

Accepted 24 July 2013

*Corresponding Author

E-mail: ch2280@korea.kr 


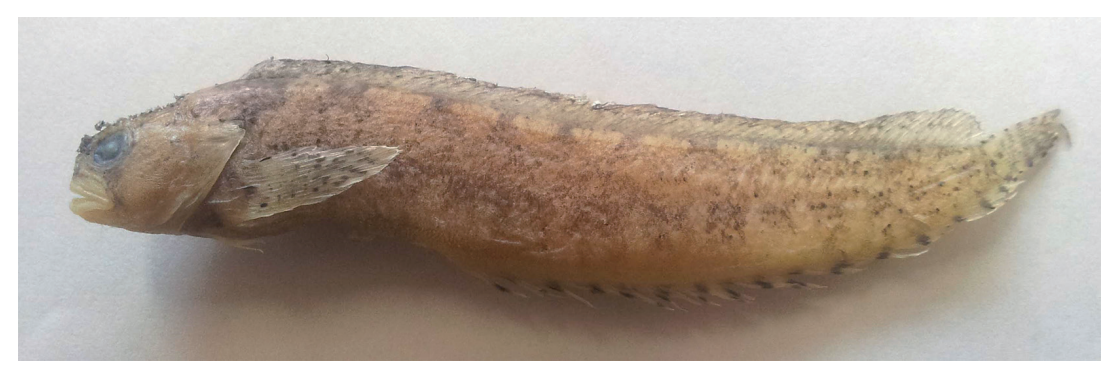

Fig. 1. Chirolophis saitone, NFRD 20110530, 75.9 mm standard length, bottom trawl, West Sea.

\section{Description}

Counts for the present specimen are shown in Table 1. Measurements are presented as a percentage against SL: body depth 18.3; head length 19.2; upper jaw length 6.1 ; snout length 2.8; eye diameter 4.2; interorbital length 3.8 ; predorsal fin length 17.9; prepectoral fin length 19.1; preanal fin length 40.5; pectoral fin length 19.1; pelvic fin length 6.3 .

Body moderately elongate, compressed posteriorly, and covered with minute cycloid scales but head entirely naked; head slightly small; snout length very short, its length being shorter than the eye diameter; mouth small, maxilla extends to anterior edge of pupil, interorbital space narrow and flat; lower jaw protruding slightly beyond upper jaw; teeth small, arranged in two alternating rows and forming a closely set single cutting edge; dorsal fin base long, origin of dorsal fin located a little before the end of the head, continuing to caudal fin base; pectoral fin large, extending below to eighth dorsal spine; pelvic fins small, somewhat longer than eye diameter; lateral line represented by a short row of four openings of the sensory canal above pectoral fins; numerous tentacles present on head, three pairs of branched cirri above eye, first one longer than others; one pair on snout and three pairs behind eye.

\section{Color when fresh}

Body light brownish with 12 dark blotches, eye and dorsal fin base; body and head mottled; belly yellowish; dorsal fin membrane light brown with dusky mottle; anal fin light yellow with 15 vertical rows of dark spots; pectoral fin light brown with white edge; pelvic fin white; caudal fin light brown with 4 5 vertical dark bands.

\section{Color in alcohol}

Body dark brownish with 12 vertical dark blotches; row of smaller dark spots present along anal fin base; body and head mottled; dorsal and pectoral fin membranes brown with dusky mottle; pelvic fin white; caudal fin brown with 4-5 vertical dark bands.

\section{Distribution}

Known from northern seas and Bisan Seto of Japan, Bohai Sea (Hatooka, 2002; Liu et al., 2005), and southern coastal waters of the Yellow Sea, Korea (present study).

\section{Remarks}

The present specimen, which was collected from southern coastal waters of the Yellow Sea, Korea, had 52 dorsal fin spines, an anal fin with one spines and 38 soft rays, a caudal fin with four vertical dark bands and an orbital region with three pairs of branched cirri. The morphological characters of the specimen matched species descriptions given in previous

Table 1. Comparison of morphological characters of Chirolophis saitone observed in this study and previously reported

\begin{tabular}{lccc}
\hline Morphological characters & Present study & Shiogaki (1981) & Liu et al. (2005) \\
\hline Individuals & 1 & 8 & 1 \\
Standard length (mm) & 75.9 & $82.0-55.0(95)$ & 87 \\
Counts & & & LIV \\
Dorsal fins & LII & LI-LIV (LI) & 15 \\
Pectoral fins & 15 & $13-15(14-15)$ & I, 4 \\
Pelvic fins & $\mathrm{I}, 4$ & $\mathrm{I}, 4(\mathrm{I}, 4)$ & $\mathrm{I}, 38$ \\
Anal fins & $\mathrm{I}, 38$ & $\mathrm{I}, 36-38(36)$ & 12 \\
Branched caudal fins & 14 & $13-15$ (damaged) & - \\
Vertebrae & 56 & $55-57(56)$ & \\
\hline
\end{tabular}

The indicate holotype in parenthesis. 
studies (Shiogaki, 1981; Liu et al., 2005), and all counts for the present specimen coincided with the C. saitone of Holotype (Table 1). C. saitone is morphologically similar to $C$. japonicus, but the former is distinguished from the latter by having a dorsal fin with 50-55 spines (vs. 60-63 spines for C. japonicus), an anal fin with 36 38 rays (vs. 45-47 for $C$. japonicus), and an orbital region with three pairs of branched cirri (vs. two pairs) (Fig. 1) (Hotooka, 2002). We propose a new Korean name, "Jak-eun-goe-do-ra-chi", for C. saitone.

\section{Acknowledgements}

This work was funded by a grant from the National Fisheries Research \& Development Institute(RP-2013-FR-060).

\section{References}

Hatooka K. 2002. Stichaeidae. In: Fishes of Japan with Pictorial Keys to the Species. English ed. Nakabo T, ed. Tokai Univ Press, Tokyo, JP, pp. 1046-1054
Hubbs CL and Lagler KF. 2004. Fishes of the Great Lake Region. University of Michigan Press, Ann Arbor, MI, US.

Jordan DS and Snyder JO. 1902. A review of the blennoid fishes of Japan. Proc U S Natl Mus 25, 441-504. http://dx.doi.org/10.5479/ si.00963801.25-1293.441.

Kim IS, Choi Y, Lee CL, Lee YJ, Kim BJ and Kim JH. 2005. Illustrated Book of Korean Fishes. Kyohak Publishing Co. Ltd., Seoul, KR (in Korean).

Lindberg GU and Krasyukova ZV. 1975. Fishes of the Sea of Japan and the adjacent areas of the Sea of Okhotsk and the Yellow Sea. 4 Akad Nauk SSSR Leningrad, RU (in Russia).

Liu J, Tian M and You F. 2005. Taxonomic reexamination of the genus Chirolophis in China waters. Chin J Oceanol Limnol 23, 199-203.

Makushok VM. 1958. The morphological and classification of the northern blennioid fishes (Stichaeoidae, Blennioidei, Pisces). Trud Zool Inst Akad Nauk SSSR 25, 3-129 (in Russia).

Shiogaki M. 1981. Redescription of the stichaeid fish Chirolophis saitone. Jpn J Ichthyol 28, 129-134.

Ueno T. 1966. Fishes from the waters of Hokkaido. 20. Stichaeidae, Zaproridae, Ptilichthyidae, Pholidae and Anarichadidae. Hokusuishi Geppo 23, 430-443 (in Japanese). 